\title{
Evaluation of the Impact of Natural Microcystin-LR Extract on Brine Shrimp as an Invertebrate Bioassay Model
}

\author{
Piyathilaka P.* and Manage P.M. \\ Department of Zoology, University of Sri Jayewardenepura, Nugegoda, Sri Lanka \\ *mapcpiyathilaka@gmail.com
}

\begin{abstract}
Frequent occurrences of toxic cyanobacteria dominantly Microcystis aeruginosa bloom are becoming a nuisance problem in Sri Lankan reservoirs in conformity with its global environmental and health issues. Most of cyanobacteria produce heat stable cyanotoxins which have potent health impacts. Many researchers have focused on pure cyanobacterial toxins and little was known about the toxic effect of natural cyanobacteria. The present study was carried out to investigate the effect of natural cyanobacterial toxins on Artemia salina (Brine shrimp) as a bioassay. The toxin, Microcystin LR was extracted from bloom samples collected from Beira and Borelesgamuwa Lakes. Both water bodies were dominated by cyanobacterium $M$. aeruginosa, which may contain toxic and non toxic strains. Density of $M$. aeruginosa at the sampling occasion in Beira Lake was $9.64 \times 10^{5}$ cells $/ 1$ and in Boralesgamuwa Lake was $5.31 \times 10^{5}$ cells/l respectively. One liter of lake water was filtered through GF/C glass microfiber filters $(47 \mathrm{~mm})$ and the filter disks with entrapped cyanobacterial cells were ultrasonicated with $20 \mathrm{ml}$ of $100 \%$ methanol for 5 minutes and then the methanolic extract was filtered and HPLC-DAD analysis was done to quantify the Microcystin (MC)-LR. MC-LR in Beira Lake was $17.13 \pm 0.02 \mu \mathrm{g} / \mathrm{ml}$. In Borelesgamuwa Lake MC-LR was not detected at the sampling occasion. Methanol in the extract was evaporated and subsequently a known weight of residue was re-suspended in $2 \mathrm{ml}$ of filtered sea water to make stock solutions of crude extracts to use for the bioassay. Artemia eggs were purchased and allowed to hatch with continuous aeration in filtered sea water under continuous white fluorescent light for $18 \mathrm{~h}$. After incubation newly hatched naupli of Artemia were collected. For the bioassay about 30 Artemia naupli were inoculated into each well in 96-well microplate. To confirm the initial number of naupli in each well, counting was performed under the microscope. MC-LR standard and extracts from Beira and Boralesgamuwa Lakes were used to prepare toxin (MC-LR) at final concentration series of $0.1,0.5,1.0,2.0,5.0,10.0,20.0$ and $50.0 \mu \mathrm{g} / \mathrm{ml}$. Number of dead individuals were counted in each well after $6,12,18,24$ and 48 hours incubation. $\mathrm{EC}_{50}$ (50\% effective concentration) values were assessed using non-linear regression by Graph Pad Prism software. $\mathrm{EC}_{50}$ value of MC-LR standard was $4.78 \mu \mathrm{g} / \mathrm{ml}$ after $6 \mathrm{~h}$ incubation. However, $\mathrm{EC}_{50}$ values of cyanobacterial crude extracts from Beira and Boralesgamuwa lakes at the same incubation period was 4.98 and $9.83 \mu \mathrm{g}$ dry weight $/ \mathrm{ml}$ respectively. The results showed that the standard MC-LR and cyanobacterial crude extracts from Beira Lake had almost similar EC $_{50}$ value while Boralesgamuwa Lakes was significantly deviated and having higher $(\mathrm{p}<0.05) \mathrm{EC}_{50}$ value. The higher toxicity of Beira Lake crude extract was due to presence of MC-LR in the extract. As confirmed by the HPLC, MC-LR was not detected in the extract prepared from Boralesgamuwa Lake. Though the extracts showed toxicity effect on Artemia reveal that the toxicity may due to other cyanotoxin variants present in the extracts. Further, it was detected that decreasing tendency of $\mathrm{EC}_{50}$ values along with the increasing incubation periods for all extracts and standard.
\end{abstract}

Keywords: Artemia naupli, Cyanobacteria, Crude extracts, Microcystin LR, $\mathrm{EC}_{50}$ 